\title{
The influence of tobacco policies in schools of Peshawar
}

Waqar Ali, Faran Aziz Khattak, Khizer Habib Khattak, Mohammad Bilal Anwar, Anum Ashfaq, Nadira Shakoor, Ghazanfar Khan, Nida Wadood, Mohammad Asim, Kainat Bukhari

\section{Submitted}

June 10,2021

Accepted

July 14, 2021

\section{Author Information}

Dr. Waqar Ali

Associate Professor,

Department of Community

Medicine, Northwest School

of Medicine, Peshawar, KP,

Pakistan

(Corresponding Author)

Email: Dr Waqar Ali

dr.waqarali@nwsm.edu.pk

From: Rehman Medical Institute, Peshawar, KP,

Pakistan.

House Officers

Faran Aziz Khattak

Khizer Habib Khattak

Mohammad Bilal Anwar

Anum Ashfaq

Nadira Shakoor

Ghazanfar Khan

Nida Wadood

Mohammad Asim

Kainat Bukhari

Citation: Ali W, Khattak FA, Khattak KH, Anwar MB,

Ashfaq A, Shakoor N, et al.

The influence of tobacco policies in schools of Peshawar. J Rehman Med Inst. 2021 Jul-Sep;7(3):21-5.

\section{ABSTRACT}

Introduction: Tobacco use has become quite common in school students worldwide and Pakistan is one of those countries massively affected. Data about implementation of tobacco control policies in schools of Peshawar city are scanty, with consequences for the health of students and school staff.

Objectives: To evaluate the implementation of tobacco control policies in schools, and the effect these policies have on tobacco use among students.

Material \& Methods: A cross sectional study was conducted among 3 private and 3 public schools of Peshawar city. Self-structured Questionnaires were used to collect data from school administration and the students. Schools were selected through simple random sampling. Classes 8, 9 and 10 were selected from each school and one section was selected from each class randomly. Students were selected through systematic sampling in which every third student was selected from each row. The age group of study subjects ranged from 12 to 18 years.

Results: Out of the 230 students that participated in the study, $51.3 \%$ were from the age group $15-18$ years and $48.7 \%$ students were in the age group 12-14 years. Amongst these, $6.52 \%$ of students reported using tobacco products. Of 6 schools included in the study, 4 were unaware of the latest tobacco control policy developed by Khyber Pakhtunkhwa (KP) government for schools. Of the remaining 2 schools, only one was effectively implementing the policy, in which $8.10 \%$ students were regular users of tobacco compared to $5.4 \%$ of students from schools not following the tobacco policy. The schools unaware of tobacco policies had $6.4 \%$ students using tobacco.

Conclusion: Two-thirds of the schools were unaware of any Tobacco Policy. An almost total lack of policy implementation was observed in the schools studied, even among the schools aware of the policy.

Keywords: Tobacco use; Siblings; Schools; Students; Government.

The authors declared no conflict of interest. All authors contributed substantially to the planning of research, data collection, data analysis, and write-up of the article, and agreed to be accountable for all aspects of the work.

\section{INTRODUCTION}

According to World Health Organization (WHO), Pakistan is one of the 15 countries worldwide with increased health problems due to tobacco use. In Pakistan, smoking has increased by $30 \%$ (compared to figures in 1998) with $19 \%$ of adults aged 18 and above smoking daily, and 60,000 annual deaths due to tobacco-related diseases. ${ }^{1}$ Many causes have been attributed to the prevalence and acceptance of smoking in Pakistan, including peer pressure, social requirements, relief of anxiety, stress, anger, frustration, and the addictive nature of nicotine in cigarettes. ${ }^{2}$

Tobacco use and addiction most often begin during youth. In a WHO survey conducted in 2013, it was observed that $10.7 \%$ of all youth $(13.3 \%$ boys and $6.6 \%$ girls) in Pakistan used tobacco or a tobacco product. Moreover, $10.5 \%$ men, $3.5 \%$ women, and $7.1 \%$ of adults used smokeless tobacco daily. ${ }^{3}$ According to a study, borrowing cigarettes from friends was reported among 50\% of adolescent smokers; easy availability plays a causal role in the increasing prevalence of adolescent smoking. ${ }^{4}$

According to a study in 2007 in Karachi, Pakistan, smokeless tobacco use was higher than cigarette smoking among high school male students $(16.1 \%$ versus $13.7 \%$ respectively). Another article from Pakistan showed that the chance of a person smoking increases by $40 \%$ with each additional person who smokes in the participant's home (i.e. parent, sibling) and it increases by 53\% with each additional close friend who is a smoker. ${ }^{6}$

Smokeless tobacco (SLT) is an extensively used term that includes various types of tobacco products (i.e. snuff, 'pan' etc.) that are either consumed orally or are taken via the nose. In approximately 115 countries, more than 300 million adults consume SLT in various forms; most of these consumers (89\%) are concentrated in South Asian countries. During the years 2004 to 2013, chewing of SLT among adolescents increased substantially from approximately $7 \%$ to $15 \%$ in the South East Asian Regions. ${ }^{7}$ SLT use is accepted in South Asian countries as an appropriate component of the cultural and social norms of society. 
When young individuals start using SLT (which starts at a very young age of nearly 15 years), they become dependent on it (as smokeless tobacco is the fourth most commonly abused substance after caffeine, alcohol and nicotine due to their simultaneous stimulant and relaxant effects). Nicotine and nitrosamines that are present in SLT cause oral and oropharyngeal cancers and are the cause of more than 0.25 million deaths globally. ${ }^{7}$

The use of tobacco in any form is unsafe. Among different types of tobacco, the most commonly sold is cigarette which accounts for $96 \%$ of the total sales. ${ }^{8}$

To control the increasing use of tobacco among students, schools can play an important role by implementing tobacco control policies. ${ }^{9}$ Students also start doing it by observing their favorite teachers who smoke, according to a study conducted in South Delhi on students ranging from 14 to 19 years. ${ }^{10}$ Apart from their academic environment, the ambiances in their homes regarding levels of restrictions on tobacco use, and the friend circle they find themselves in, appear to have significant effect on their tendency to develop tobacco use.

A study conducted in Canada which examined how smoking policies and programs are associated with smoking behavior of Grade 10 students showed that the students attending the schools without smoking policies are more likely to be occasional smokers. ${ }^{11}$

However studies have shown that the effects of school tobacco policies are not always encouraging in preventing tobacco use by students as an article published in Scotland had a similar aim to investigate the current status of smoking policies in Scottish schools, and the relationship between policy status, enforcement of smoking restrictions and perceptions of smoking behavior among pupils and teachers. There was no relation found between the school written policy and pupil smoking. ${ }^{12}$

In this cross-sectional study, involving 3 public and 3 private schools, we aimed to evaluate the implementation of tobacco control policies in schools, and the effect these policies have on tobacco use among students.

\section{MATERIALS \& METHODS}

A cross-sectional study was conducted in private and public schools of Peshawar city ( 3 from private sector and 3 from public sector). The schools were selected through simple random sampling. Students of $8^{\text {th }}, 9^{\text {th }}$ and $10^{\text {th }}$ classes were selected. One section from each class was selected through simple random sampling technique. The students in every section were selected through systematic sampling technique in which every third student in a row was selected. The ages ranged from 12 to 18 years of age. We contacted the administrations of the selected schools through letters and phone calls to take permissions to collect data. After the approval, a date was fixed to collect the data. Originally, we had planned to include 9 schools in this study. Due to reasons of their own, we weren't allowed to collect data in 3 of these schools. Two self-structured questionnaires were prepared under the supervision of our research supervisor, one for each of the school administrations, and one for the students. Consent was taken from the students and the institutions and they were taken under confidence that any personal data they provide will be kept confidential. The questionnaire directed at the administration had 9 questions which tried to evaluate the school tobacco control policies. The questionnaires directed at the students had questions regarding their tobacco use habits.

We entered the questionnaires in the SPSS version 24.0. We used Chi-square cross-tabulations and frequencies. We tried to find associations between school tobacco control policies and student tobacco use. Chi-square test is used to find the associations between any two categorical variables.

\section{RESULTS}

Out of the 230 students that participated in the study, $51.3 \%$ were from the age group $15-18$ (118). $48.7 \%$ students were in the age group 12-14 years (112) (Fig.1).

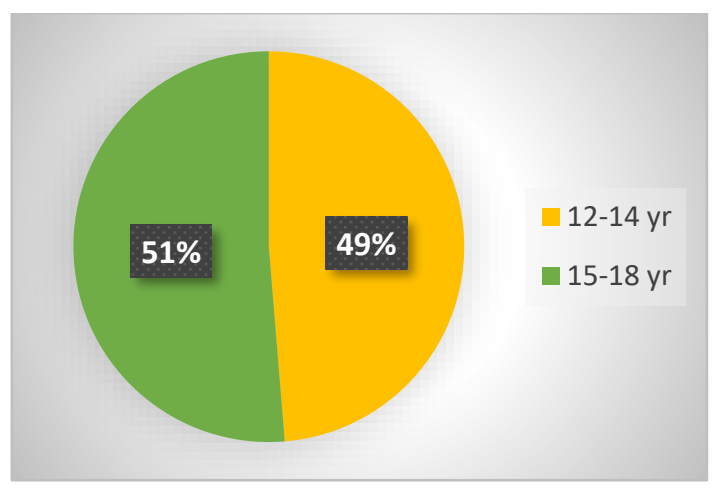

Fig.1 Percentage of Age group of Students

Out of the total 230,15 students $(6.52 \%)$ reported using tobacco products; 12 out of these students smoked tobacco with 06 being regular smokers over the past 30 days. Three students reported using the smokeless forms of tobacco exclusively. There were 06 $(2.61 \%)$ students who were using both forms of tobacco. Out of those six who smoked regularly, 2 were also non-regular users of smokeless tobacco and 2 did not use smokeless tobacco at all. Out of those who smoked occasionally, 2 were also non-regular users of smokeless tobacco. Among non-smoking students, one reported regular use of smokeless tobacco, while 3 were nonregular users of smokeless tobacco.

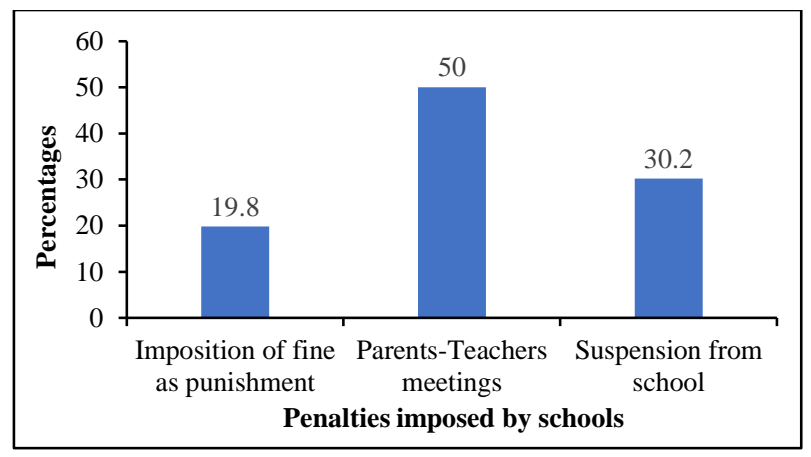

Figure 2: Percentages of penalties imposed by Schools

According to Figure 2, the major penalty that was imposed by schools on their students for tobacco use was informing their parents through Parents-Teacher meetings (50\%), followed by students' suspension $(30.2 \%) ; 19.8 \%$ schools imposed fine as punishment for tobacco use. 
It was found that amongst the 6 schools included in the study, 4 were unaware of the latest tobacco control policy developed by government for schools. Of the remaining 2 schools, only one was effectively implementing the policy (Fig.3).

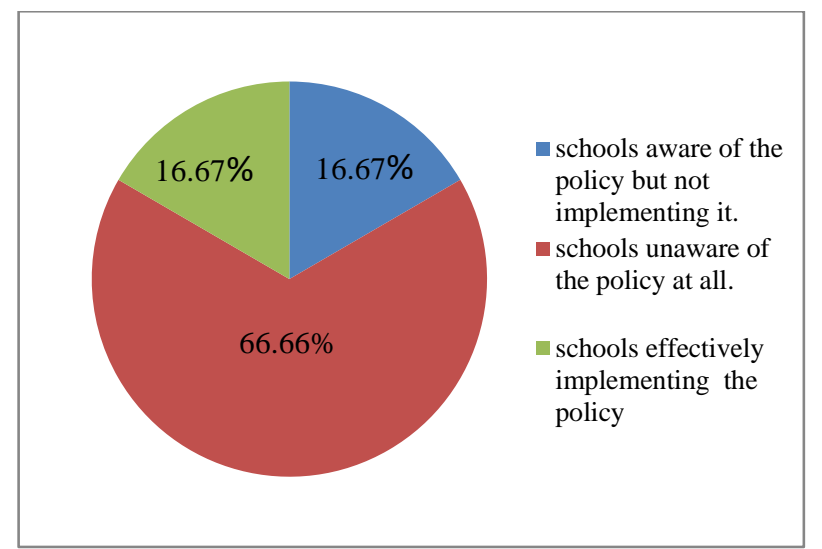

Figure 3: Awareness amongst schools regarding latest school tobacco control policy

Figure 4 shows the effect of implementation of the latest government policy regarding tobacco use in schools; $8.10 \%$ students enrolled in schools following the tobacco policy were regular users of tobacco; $5.4 \%$ students enrolled in those schools not following the tobacco policy were found to be regular tobacco users. Schools unaware of tobacco policies were having student tobacco use percentage of $6.4 \%$.

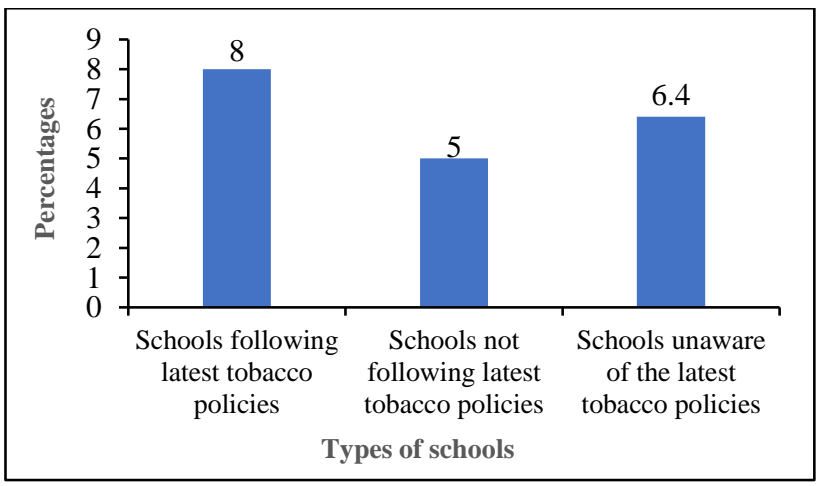

Figure 4: Effect of school policies on student tobacco use.

There was no significant association between students' smoking habits (for tobacco and smokeless tobacco) and implementation of government policy for tobacco control by schools ( $p>0.05$ ), as shown in Table 1.

Table 1: Students' smoking habits (tobacco and smokeless tobacco) * Has the school adopted the guidelines regarding tobacco control given in the latest government policy for tobacco control (November 2018)? Crosstabulation (Chi Square)

\begin{tabular}{|c|c|c|c|c|c|c|}
\hline \multirow[t]{2}{*}{$\#$} & \multirow[t]{2}{*}{$\begin{array}{l}\text { Students' smoking habits } \\
\text { (Tobacco) }\end{array}$} & \multicolumn{3}{|c|}{$\begin{array}{l}\text { Has the school adopted the guidelines regarding } \\
\text { tobacco control given in the latest government } \\
\text { policy for tobacco control (November 2018)? }\end{array}$} & \multirow[t]{2}{*}{ Total } & \multirow[t]{2}{*}{ p value } \\
\hline & & Yes & No & Unaware of policy & & \\
\hline 1. & Smoked daily for the past 30 days & $02(33.3 \%)$ & 0 & $04(66.7 \%)$ & 06 & \multirow[t]{4}{*}{$>0.05$} \\
\hline 2. & Smoked at least once in the past 30 days & $01(16.7 \%)$ & $01(16.7 \%)$ & $04(66.7 \%)$ & 06 & \\
\hline \multirow[t]{2}{*}{3.} & Not smoked at all in the past 30 days & $35(16.1 \%)$ & $37(17.0 \%)$ & $146(67.0 \%)$ & 218 & \\
\hline & $\begin{array}{c}\text { Total } \\
\end{array}$ & $38(16.5 \%)$ & $38(16.5 \%)$ & $154(67.0 \%)$ & 230 & \\
\hline \multirow[t]{2}{*}{$\#$} & \multirow[t]{2}{*}{$\begin{array}{l}\text { Students' smoking habits } \\
\text { (Smokeless Tobacco) }\end{array}$} & \multicolumn{3}{|c|}{$\begin{array}{l}\text { Has the school adopted the guidelines regarding } \\
\text { tobacco control given in the latest government } \\
\text { policy for tobacco control (November 2018)? }\end{array}$} & \multirow[t]{2}{*}{ Total } & \multirow[t]{2}{*}{ p value } \\
\hline & & Yes & No & Unaware of policy & & \\
\hline 1. & $\begin{array}{l}\text { Used smokeless tobacco at least once in } \\
\text { the past } 30 \text { days }\end{array}$ & $02(22.2 \%)$ & $01(11.1 \%)$ & $06(66.7 \%)$ & 09 & $>0.05$ \\
\hline \multirow[t]{2}{*}{2.} & $\begin{array}{l}\text { Not used smokeless tobacco at least } \\
\text { once in the past } 30 \text { days }\end{array}$ & $36(16.3 \%)$ & $37(16.7 \%)$ & $148(67.0 \%)$ & 221 & \\
\hline & $\begin{array}{c}\text { Total } \\
\end{array}$ & $38(16.5 \%)$ & $38(16.5 \%)$ & $154(67.0 \%)$ & 230 & \\
\hline
\end{tabular}

\section{DISCUSSION}

This cross-sectional study is one of the few studies that have been conducted in our region. Researchers have conducted this type of study on college and university students but were not conducted on school level which a study in Canada shows is a vulnerable age group for initiation of Tobacco use. ${ }^{13}$

Our study showed that $51.3 \%$ of the school students who used tobacco products were from the age group of $15-18$ and $48.7 \%$ students were in the age group of 12-14 years. A similar study was conducted in different colleges of Karachi in which 19.2\% of students who smoked were in the age group of 15-17 years and $26.5 \%$ in $18-20$ years and $65 \%$ were in 21 and above years. ${ }^{14}$ Another study conducted in Quebec secondary schools, Canada showed that $3.8 \%$ of boys aged 13 years and $21.0 \%$ of boys aged 16 years smoked daily. ${ }^{13}$

Schools were assessed for awareness regarding the latest tobacco control policy of government; 4 out of 6 schools of our study were unaware of this latest policy. Of the remaining 2 schools only one of them was effectively implementing the policy. This study shows that $66.66 \%$ of the schools of Peshawar are unaware of any school tobacco policies. This lack of awareness of the schools' administrations regarding Tobacco control policies and the failure of implementation of these policies can encourage the students to initiate tobacco use. On the other hand, the Center for Disease Control and Prevention (CDC) in USA recommends that each school enforce a school policy on tobacco use and support cessation efforts amongst students. They suggest that clearly 
articulated school policies applied fairly and consistently could help students decide not to use tobacco. ${ }^{15}$ Another survey conducted in Wales regarding the association between the smoking policies and its prevalence among adolescents showed that they had a consistent and statistically significant association between these two. ${ }^{16}$

However our study did not suggest any association between enforcing a school policy on tobacco use and students' habit of tobacco use, as $8.10 \%$ of students enrolled in schools following the tobacco policy were regular users of tobacco compared to $5.4 \%$ of students enrolled in those schools not following the tobacco policy. Schools unaware of tobacco policies were having $6.4 \%$ students using tobacco. This opposing result of our study was largely affected by the unawareness of most of the schools regarding the tobacco policies. So assessing the effectiveness of these policies became meaningless.

Our study showed that the tobacco users were higher in private schools which is $3.4 \%$ and $1.7 \%$ in public schools, but according to another study conducted in schools of Karachi showed that there is a higher prevalence of smoking in government schools which is $18.3 \%$ and $8.1 \%$ in private schools which was due to better educational activities and a close monitoring system. ${ }^{17}$

We also tried to find out if the school staff was permitted to use tobacco inside or outside premises as school staff using tobacco has influence on students which is also shown by a data collected from a study conducted in seven European countries regarding student exposure to teacher smoking. The study showed that students were less likely to be exposed to indoor tobacco smoke in schools where proper smoking policies were implemented. ${ }^{18}$ Hence in our study, no school allowed staff to smoke indoors or outdoors.

\section{CONCLUSION}

Majority (two-thirds) of schools studied were not aware of the Tobacco Control Policy for Schools developed by the Government of Khyber Pakhtunkhwa province. Implementing of effective policy was lacking in almost all the schools included in the study.

\section{LIMITATIONS}

There may have been selection bias because the sample size we had selected for our study was quite small so as a result a vast majority of schools are missed out which has serious effects on the results. Along with that, few of the schools did not allow us to collect data from their students due to reasons of their own which reduced our number of schools hence again affecting the study.

\section{RECOMMENDATIONS}

School students are at a vulnerable age for initiation of tobacco. Therefore special attention needs to be addressed to this issue by enforcing proper tobacco control policies by the government. Strict monitoring should be carried out of schools to assess the effectiveness of those policies because if not controlled at school level, this problem can turn out to be far worse in future affecting deleteriously the lives of these students.

\section{REFERENCES}

1. Teenage smoking on the rise | Pakistan Today. [cited 2021 Mar 1]; Available from: https://www.pakistantoday.com.pk/2013/0 8/16/teenage-smoking-on-the-rise/

2. Nizami, S., Sobani, Z., Raza, E., Baloch, N., Khan, J. Causes of smoking in Pakistan: an analysis of social factors. JPMA. 2011;61(2):198-201. Available at: https://ecommons.aku.edu/pakistan_fhs_m c_med_pulm_critcare/6.

3. WHO, CDC. Global Youth Tobacco Survey. Country Fact Sheets. Pakistan Islamabad (Ages 13-15). [Online]. Available from: http://www.emro.who.int/images/stories/tfi /documents/GYTS_FS_PAK_R1.pdf (accessed 22 May 2021).

4. Rozi S, Akhtar S, Ali S, Khan J. Prevalence and factors associated with current smoking among high school adolescents in Karachi, Pakistan. Southeast Asian J Trop Med Public Health. 2005 Mar;36(2):498-504.

5. Rozi S, Akhtar S. Prevalence and predictors of smokeless tobacco use among highschool males in Karachi, Pakistan. East Mediterr Health J. 2007;13(4):916-24.

6. Sharma R, Grover V, Chaturvedi S. Tobacco use among adolescent students and the influence of role models. Indian $\mathrm{J}$
Community Med. 2010 Apr;35(2):272-5. doi: 10.4103/0970-0218.66891.

7. Hussain A, Zaheer S, Shafique K. Schoolbased behavioral intervention to reduce the habit of smokeless tobacco and betel quid use in high-risk youth in Karachi: a randomized controlled trial. PLoS One. 2018;13(11):e0206919.

8. WHO. Types of tobacco use. [Webpage]. [cited 2021 Mar 1]. Available from: https://www.afro.who.int/sites/default/files /2017-

09/Chapter\%201.\%20Types\%20of\%20tob acco\%20use_1.pdf

9. Lovato CY, Sabiston CM, Hadd V, Nykiforuk CIJ, Campbell HS. The impact of school smoking policies and student perceptions of enforcement on school smoking prevalence and location of smoking. Health Educ Res. 2007 Dec;22(6):782-93. 10.1093/her/cyl102.

10. Jha $P$, Ramasundarahettige $C$, Landsman V, Rostron B, Thun M, Anderson RN, et al. 21st-Century hazards of smoking and benefits of cessation in the United States. N Engl J Med. 2013 Jan 24;368(4):341-50. [cited 2021 Mar 1], Available from: http://www.nejm.org/doi/10.1056/NEJMsa

\section{8.}

11. Murnaghan DA, Leatherdale ST, Sihvonen M, Kekki P. A multilevel analysis examining the association between schoolbased smoking policies, prevention programs and youth smoking behavior: evaluating a provincial tobacco control strategy. Health Educ Res. 2008 Dec;23(6):1016-28. https://doi.org/10.1093/her/cyn034

12. Dawn Griesbach, Jo Inchley, Currie C. More than words? The status and impact of smoking policies in Scottish schools. Health Promotion International. Health Promot Int. 2002 Mar;17(1):31-41. doi: 10.1093/heapro/17.1.31.

13. Barnett TA, Gauvin L, Lambert $M$ O’Loughlin J, Paradis G, McGrath JJ. The influence of school smoking policies on student tobacco use. Arch Pediatr Adolesc Med. 2007;161(9):842-8. doi:10.1001/archpedi.161.9.842.

14. Ahmed R, ur Rashid R, McDonald PW, Ahmed SW. Prevalence of cigarette smoking among young adults in Pakistan. J Pak Med Assoc. 2008;58(11):597-601.

15. Centers for Disease Control and Prevention. Guidelines for school health programs to prevent tobacco use and addiction. MMWR 
1994;43(No. RR-2). Available from: https://www.cdc.gov/mmwr/pdf/rr/rr4302. pdf

16. Moore L, Roberts C, Tudor-Smith C. School smoking policies and smoking prevalence among adolescents: Multilevel analysis of cross-sectional data from Wales.
Tob Control. 2001;10:117-23.

17. Rozi S, Butt ZA, Akhtar S. Correlates of cigarette smoking among male college students in Karachi, Pakistan. BMC Public Health. 2007;7:312. https://doi.org/10.1186/1471-2458-7-312.

18. Wold B, Torsheim T, Currie C, Roberts C.
National and school policies on restrictions of teacher smoking: a multilevel analysis of student exposure to teacher smoking in seven European countries. Health Educ Res. 2004 Jun;19(3):217-26. doi: 10.1093/her/cyg029. 